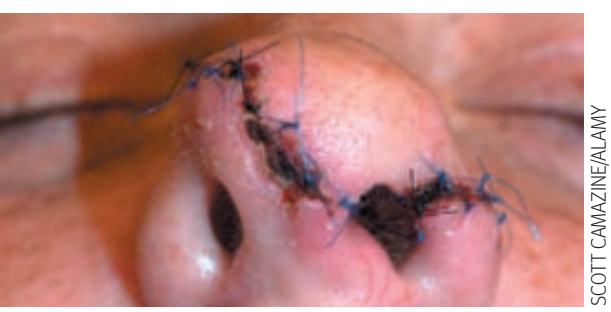

\section{DOG BITES}

\section{Education of dog owners is key to reducing attacks}

The negative opinions in Besser's personal view contrast with the positive impact of dog ownership on human health described in an editorial published in the Veterinary Record. ${ }^{12}$ The Record cites research showing that dog owners tend to be fitter, have lower blood pressure and cholesterol, and have a greater level of physiological wellbeing. ${ }^{3}$ The NHS should weigh up the cost saving implications of the above against the cost of treating dog bites. Also, the life enriching work carried out by the Guide Dogs for the Blind, Hearing Dogs for the Deaf, and Dogs for the Disabled must save the NHS thousands of pounds in carers' fees.

Education of dog owners is the key to reducing dog bites, but I disagree with Besser's suggestion that vets do little to advise owners. Animal behaviour makes up a large part of the veterinary undergraduate curriculum, and veterinary practices are conscious of the need to spend time with owners of new dogs, especially puppies, discussing dog behaviour. Many run puppy socialisation and training classes.

To suggest that neutering all dogs would solve the bite problem is naive. Dogs bite for many reasons. Neutering along with behavioural therapy can reduce the incidence of dominance aggression, but it can have an adverse effect in anxious dogs and make them more prone to displays of nervous aggression.

Katherine M Clarke veterinary surgeon Bishopton Veterinary Group, Ripon, North Yorkshire HG42QR mdkmclarke@aol.com

Competing interests: None declared.

1 Besser R. Dog attacks: it's time for doctors to bite back. BMJ 2007;334:425. (24 February.)

2 Benefits of dog ownership on human health. Vet Rec 2007;160:209.

3 Wells DL. Domestic dogs and human health: an overview. BrJ Health Psychol 2007;12:145-56.

\section{Science, rather than politics, is needed for progress}

It is a shame that in the UK, in contrast to some other European countries, it is increasingly difficult for owners fully to incorporate their dogs into their lives, as "No dogs allowed" seems to have become the norm. As a result people do not understand normal canine behaviour and we must seek to educate them accordingly. In addition to the Blue Dog programme mentioned by Besser, ${ }^{1}$ the Canine Commandments by Kendal Shepherd (who is also developing an educational package compatible with requirements within the national curriculum in personal, social and health education for older children) is being supported by the Association for the Study of Animal Behaviour. ${ }^{2}$

Further research and funding for such initiatives is needed. At present there is a dearth of knowledge concerning the circumstances of most attacks, simply because we don't ask the right questions. With this in mind, I propose an initial scoping meeting to identify research priorities for prevention and would be delighted to hear from colleagues willing to contribute to an initial discussion.

Daniel S Mills professor of veterinary behavioural medicine University of Lincoln, Lincoln LN2 2LG dmills@lincoln.ac.uk Competing interests: None declared.

1 Besser R. Dog attacks: it's time for doctors to bite back. BMJ 2007;334:425. (24 February.)

2 Shepherd K. The canine commandments. Bristol: Broadcast Books, 2007.

\section{MALARIA}

\section{Stop ambiguous messages on malaria diagnosis}

Reyburn et al's findings on malaria case management in endemic areas are worrying. ${ }^{1}$ Part of the problem is due to ambiguous messages provided by malaria experts and national guidelines on how to take action on the result of a malaria test. Undoubtedly, the ambiguity of national malaria control programme guidelines on the management of suspected malaria in children younger than 5 years is a factor. ${ }^{2}$

In Tanzania the recommendation is to perform microscopy/rapid diagnostic tests for malaria. If results are negative and there are no signs and symptoms of severe disease in a child under 5 years, treat as uncomplicated malaria and look for another condition. ${ }^{3}$ Similar inconsistency is found in the Ugandan guidelines.

The risk of missing a true malaria case in the event of a negative test and the resulting consequences have recently been evaluated thoroughly in Uganda. ${ }^{4}$ Febrile children were not given antimalarials when the results of microscopy were negative (rate of malaria test positivity: $32 \%$ ). Only two malaria cases out of 2359 febrile episodes were missed; both patients consulted the next day because of persisting fever and were treated for uncomplicated malaria on the basis of new positive test results. In parallel, 464 non-malaria causes of fever in need of antibiotic treatment were identified. ${ }^{4}$

The assertion that feverish children under 5 years should be treated with antimalarials irrespective of the test result, because the disease has a more rapid course, is inadequate. The clinical assessment to identify danger signs early enough is crucial, but how well the test performs, and hence the trust we can have in its result, is the same in all age groups. Teaching material and guidelines should not be based on beliefs and fears but should be updated by using most recent evidence. In uncomplicated febrile illness a positive result in a malaria test means malaria and a negative result, no malaria.

Valérie D’Acremont research physician

Valerie.Dacremont@unibas.ch

Christian Lengeler senior lecturer in epidemiology

Blaise Genton senior lecturer in tropical medicine Ifakara Health Research and Development Centre, Box 78373, Dar es Salaam, Tanzania, and Swiss Tropical Institute, 4002 Basel, Switzerland

Competing interests: None declared.

1 Reyburn H, Mbakilwa H, Mwangi R, Mwerinde O, Olomi R, Drakeley C, et al. Rapid diagnostic tests compared with malaria microscopy for guiding outpatient treatment of febrile illness in Tanzania: randomised trial. BMJ 2007;334:403. (24 February.)

2 Makani J, Matuja W, Liyombo E, Snow RW, Marsh K, Warrell DA. Admission diagnosis of cerebral malaria in adults in an endemic area of Tanzania: implications and clinical description. Q J Med 2003;96:355-62.

3 National Malaria Control Programme. National guidelines for malaria diagnosis and treatment. Tanzania: Ministry of Health, 2006.

4 Njama-Meya D, Clark TD, Nzarubara B, Staedke S, Kamya MR, Dorsey G. Treatment of malaria restricted to laboratory confirmed cases: a prospective cohort study in Ugandan children. Malar J 2007;6:7. 


\section{UK recommendations for severe malaria are worrying}

We are concerned that patients with severe malaria admitted to UK hospitals will die needlessly because of the continued recommendation of an inferior antimalarial drug-quinine. ${ }^{1}$ In adults with severe malaria admitted to hospitals in temperate countries, mortality often exceeds $20 \%$. In the largest trial of severe malaria ever conducted (which enrolled 1461 patients, including 202 children), intravenous artesunate reduced the mortality due to severe malaria by one third. ${ }^{2}$ In a meta-analysis of all trials comparing artesunate and quinine in severe malaria, mortality in quinine recipients was $23 \%$ compared with $14 \%$ in artesunate recipients. As a result, the current treatment guidelines from the World Health Organization recommend artesunate above quinine for treating severe malaria in adults. ${ }^{3}$

These trials in severe malaria evaluated artesunate manufactured in China (Guilin Pharmaceutical Company). The main source of this formulation in the world, it has not yet been approved as meeting international GMP standards, yet it clearly saves lives. Do the UK authorities seriously believe that any minor imperfections in a tested formulation could outweigh a 35\% difference in mortality?

Nicholas J White professor, Nicholas PJ Day professor, Arjen Dondorp doctor, Faculty of Tropical Medicine, Mahidol University, Bangkok, Thailand nickwdt@tropmedres.ac Nicholas Anstey professor, Menzies School of Health Research, Casuarina, Darwin, NT, Australia

Competing interests: None declared.

1 Lalloo DG, Shingadia D, Pasvol G, Chiodini PL, Whitty CI, Beeching NJ, et al. UK malaria treatment guidelines, J Infect 2007;54:111-21.

2 Dondorp A, Nosten F, Stepniewska K, Day N, White NI. South East Asian quinine artesunate malaria trial (SEAQUAMAT) group. Artesunate versus quinine for treatment of severe falciparum malaria: a randomised trial. Lancet 2005;366:717-25.

3 World Health Organization. Guidelines for the treatment of malaria. Geneva: WHO, 2006.

\section{TRANSLATION SERVICES}

\section{Time to shift the debate}

Jones is correct that many people with limited English who seek NHS care are vulnerable, sick, and disempowered and have good reasons why they cannot immediately or easily learn English. ${ }^{1}$ Adams is also correct that providing a free translation service creates a perverse incentive for people to resist the social integration that could improve their health and wellbeing. ${ }^{2}$ But translating what is said is often the least problematic task faced by the professional interpreter, whose multiple (and inherently conflicting) roles also include those of advocate, cultural adviser, negotiator, broker of trust, professional friend, teacher and taxi service. ${ }^{3-5}$ Translation without careful attention to the patient's health literacy, receptiveness, and personal priorities may erode rather than enhance doctor-patient communication. ${ }^{45}$

Before we all lock horns over "paying for translation," let us shift the debate to more fruitful territory. I propose we start with three principles: (a) people most in need of healthcare are least likely to seek it or receive it; (b) citizen engagement is essential if society is to enjoy maximum health and productivity; and (c) education has a critical role in creating engagement and liberating society's most vulnerable members from oppression. Perhaps it is time to stop using NHS interpreters as bilingual parrots in medical consultations and instead develop them as community educators. My team is currently testing such an approach in a randomised trial (www. newhamuniversityhospital.co.uk/poseidon/). Trisha Greenhalgh professor of primary health care University College London, London N19 5LW p.greenhalgh@pcps.ucl.ac.uk

Competing interests: None declared.

1 Jones D. Should the NHS curb spending on translation services? BMJ 2007;334:399. (24 February.)

2 Adams K. Should the NHS curb spending on translation services? BMJ 2007;334:398. (24 February.)

3 Greenhalgh T, Robb N, Scambler G. Communicative and strategic action in interpreted consultations in primary health care: a Habermasian perspective. Soc Sci Med 2006; 63:1170-87.

4 Robb N, Greenhalgh T. "You have to cover up the words of the doctor": the mediation of trust in interpreted consultations in primary care. J Health Organ Manag 2006;20:434-55

5 Angelelli C.Medical interpreting and cross-cultural communication. Cambridge: Cambridge University Press, 2005.

\section{English classes are being cut}

Cutting translation services could be seen as "tough love" to help non-English speakers help themselves. ${ }^{1}$ In my experience of working as a general practitioner and as a psychiatrist with asylum seekers, they are usually very keen to learn English, and the rate at which they pick it up is often amazing. English classes also provide occupational therapy for those feeling depressed, traumatised, and isolated. When someone doesn't learn English, there is usually a reason.

Government policy is increasing the cost of interpreting. Interpreters historically often came from asylum seeker communities, but when the Home Office stopped asylum seekers working, this source dried up. I have often had to use the far more expensive telephone service because there has been no face to face interpreter. Now the government is planning to cut English teaching entitlement to asylum seekers aged over 19, limiting their opportunities to learn English and forcing public services to rely on interpreters even more.

Philip R Matthews staff grade psychiatrist, Newcastle General Hospital, Newcastle upon Tyne NE46BE prmatthews@doctors.org.uk

Competing interests: PRM has produced printed and web based translated materials for use with asylum seekers.

1 Adams K. Should the NHS curb spending on translation services? BMJ 2007;334:398. (24 February.)

\section{NHS REDRESS ACT}

\section{Support from the United States}

As a response to medical malpractice the NHS Redress Act $i$ is something that UK citizens should be proud of. ${ }^{1}$ In 1987, I helped start and manage a programme in a US hospital that used early disclosure and compensation (but, unlike the NHS Redress Act, without any compensation ceiling). That programme is now in its 20th consecutive year of operation, and its record has been made public. ${ }^{2}$

The disclosure of error and offer of compensation is not a risk management scheme intended to benefit the institution. It is a common sense method to help redress the damage done to patients harmed by medical error or negligence. Any benefit to the institution derives from that. If such a course is pursued competently and confidently, the NHS Redress Act probably will result in more paid claims than now. However, the diminished anger resulting from the proper treatment of injured patients should mitigate monetary demands aimed mainly at punishing the NHS. This, and the decline in litigation and its costs, should result in lower total liability expenses at the same time that it benefits deserving patients. Some persons with undeserving claims may attempt to profit from the scheme. But this can be prevented by performing complete investigations (to defend the NHS in the event of litigation) and steadfastly declining to compensate such plaintiffs. With time, this will discourage undeserved claims.

Steve Kraman physician, University of Kentucky, 740 South Limestone Street, Lexington, KY 40505, USA sskram01@uky.edu

Competing interests: None declared.

1 Furniss R, Ormond-Walshe S. An alternative to the clinical negligence system. BMJ 2007;334;400-2. (24 February.)

2 Kraman SS, Hamm G. Risk management: extreme honesty may be the best policy. Ann Intern Med 1999;131:963-7. 


\section{ACADEMIC MEDICINE}

\section{Process of science counteracts enthusiasum}

In their open letter Ioannidis et al fail to address a key question: why do so few medical doctors now find academic medicine attractive? ${ }^{1}$ Academic clinicians are enthused by the science they work in and often communicate this enthusiasm to their students-surely this should attract more into the field?

No one wants dares mention that the process of science has rendered the practice of science unpalatable to all but the most dedicated. The overwhelmingly bureaucratic processes of so called research governance and the complexity and time consuming aspects of seeking research funding are extremely unattractive sides to modern clinical science. Unless we admit that these processes are no longer suitable, and face the fact that they are putting off more people than they are helping, we will continue to see academic medicine dwindle away.

W A Carrock Sewell visiting professor of immunology University of Lincoln, Lincoln LN6 7TS

carrock.sewell@nlg.nhs.uk

Competing interests: None declared.

1 Ioannidis JPA, Ahmed T, Awasthi S, Clarfield AM, Clark J, Dandona L, et al. Open letter to the leader of academic medicine. BMJ 2007;334:191-3. (27 January.)

\section{Acknowledge trainees' needs}

Most F2 doctors care passionately about health care, and ambitious members of the cohort are more likely to channel their efforts into clinical medicine than into academia. ${ }^{1}$ Academic medicine can seem dry and slow moving in comparison to the reality of clinical practice. Can we expect doctors with less than two years' clinical experience to take the long term view necessary for undertaking valuable research, when the time it takes to achieve worthwhile results may be longer than the overall time they have been practising? Academic leaders need to emphasise that the first three years of an academic clinical fellowship consists of $75 \%$ clinical work.

Potential clinical academics could be identified early in their training if enough attention was paid during the early years in medical school. Academic medicine does not need to recruit the brightest and best: indeed these people will often turn out to be single minded career chasers, to the detriment of future research. Instead academia needs to recognise juniors with sufficient motivation and dedication to pursue worthwhile research projects, and nurture this talent while simultaneously providing enough clinical exposure to satisfy their initial desire to practise medicine.

Anna C Bibby academic F2 doctor, University of Bristol, Bristol BS81TH annabibby@doctors.org.uk

Competing interests: None declared.

1 Ioannidis JPA, Ahmed T, Awasthi S, Clarfield AM, Clark J, Dandona $\mathrm{L}$, et al. Open letter to the leader of academic medicine. BM/ 2007;334:191-3. (27 January.)

\section{UK response}

Ioannidis et al seem to be unaware of major developments in the United Kingdom. ${ }^{1}$ Countries wishing to revitalise academic medicine might take note of new initiatives arising from a partnership between government and academic leaders. These include major investment in the clinical research base; introduction of a funded clinical academic training pathway; partnership between government and charitable funders; and successful introduction of bodies for strategic coordination of health research-the UK Clinical Research Collaboration, the National Institute for Health Research, and the Office for the Strategic Coordination of Health Research. The opportunities for translational research, speeding the application of research findings for patient benefit, have never been better.

In addition to research, selecting students who will make the best doctors is a key issue for medical schools. Member schools have developed the new UK clinical aptitude test (UKCAT) to probe qualities such as integrity, empathy, resilience, and the capacity to deal with complexity and ambiguity. Our undergraduate courses then develop these attributes to equip students to work flexibly and innovatively in the future healthcare environment. UK medical schools also have close links with the developing world and are engaged in research and training projects across the globe.

John Tooke chair, Council of Heads of Medical Schools, LondonWC1H9HD admin@chms.ac.uk Competing interests: None declared.

1 Ioannidis JPA, Ahmed T, Awasthi S, Clarfield AM, ClarkJ, Dandona L, et al. Open letter to the leader of academic medicine. BMJ 2007;334:191-3. (27 January.)

\section{Who should call the tune?}

\section{The $B M J$ of 27 January contains a} remarkable convergence about why academic medicine is in trouble-notably, invisible leaders, ghost writers, and the influence of industry. ${ }^{1-3}$

The invisible biopolitical leaders are too often preoccupied with their positions and powers. When things do not work out they try to disappear as academe and patients are left to flounder in a bureaucratic mess. The bottom line is that decision makers should be accountable to taxpayers for outcomes.

This problem is not confined to academic medicine. Consider that the Berlin Philharm onic Orchestra is state supported but governed independently. This freedom translates into high quality, without which the orchestra would lose public support. This triangular relation between freedom, performance, and accountability applies to any complex, creative human enterprise. When external controls, which are often financially manipulated by regulatory bodies, usurp freedom, the creative triangle is broken and yields neither performance nor accountability. Sound familiar? James R Philp professor emeritus of medicine University of Alabama james.philp@att.net

\section{Competing interests: None declared.}

1 Ioannidis JPA, Ahmed T, Awasthi S, Clarfield AM, Clark Dandona $L$, et al. Open letter to the leader of academic medicine. BM/ 2007;334:191-3. (27 January.)

2 Dawes K. Ghost writers need to be more visible. BMJ 2007;334:208. (27 January.)

3 Tanne JH. US guidelines often influenced by industry. BMJ 2007;334:171. (27 January.)

\section{Time for a scientific social network}

Ioannidis et al state that an aim of academic medicine must be to develop a global outlook, ${ }^{1}$ and Sandars describes the importance for doctors of building a virtual network of information sources via the internet. ${ }^{2}$

The new technology combining these two ideas-social networking websites ${ }^{3}$-could be harnessed for immense benefit to the scientific sector. A scientific social network would allow scientists to share details of their current research, ideas, and techniques and freely distribute their results. It would reduce wasteful scientific redundancy by preventing scientists from doing experiments others have done before them. It would also enable cooperation between groups across the world.

Felix E C Greaves F2 doctor, Alexander Finlayson University Hospital Lewisham, London SE136LH felix@felixgreaves.co.uk

Competing interests: FECG and AF are developing a free, open access social networking website for scientists: academicswithoutborders.org (open to public access from April 2007).

1 loannidis JPA, Ahmed T, Awasthi S, Clarfield AM, Clark J, Dandona $L$, et al. Open letter to the leader of academic medicine. BMJ 2007;334:191-3. (27 January.)

2 Sandars J. Developing a virtual personal network. $B M$ Career Focus 2007;334:13-5.

3 Jesdanun A. Facebook to open to all internet users. ABC News 2006-09-11. http://abcnews.go.com/ Technology $/$ wireStory?id=2422125 